Original Article

\title{
FORMULATION OF AN ANTI-BACTERIAL CREAM FROM PLANTOXALIS CORNICULATA ANDITS EVALUATION
}

\author{
BATHSA LIZA JOHNSON ${ }^{*}{ }^{*}$, BHANUPRAKASH ARAKAREDDY ${ }^{1}$, KEZIA K. SAM ${ }^{2}$
}

${ }^{1}$ Bharat School of Pharmacy, Mangalpally, Ibrahimpatnam, Rangareddy, Telangana, India, ${ }^{2 B h a r a t ~ I n s t i t u t e ~ o f ~ T e c h n o l o g y, ~ M a n g a l p a l l y, ~}$ Ibrahimpatnam, Rangareddy, Telangana

Email: bathsalizaj@gmail.com

Received: 17 Jun 2020, Revised and Accepted: 19 Aug 2020

\begin{abstract}
Objective: Even in areas where modern medicine is available, the interest on herbal medicines and their utilization have been increasing rapidly in recent years. Plant-derived substances and herbal medicines have recently attracted the great interest towards their versatile application as medical plants are the rich source of bioactive compounds used in traditional and modern medicine. The present work is to formulate and evaluate
\end{abstract} the antibacterial cream of oxalis corniculata extract.

Methods: The ethanolic extracts were prepared by using the maceration method.

Results: The agrochemical potential of methanolic extract, n-hexane, chloroform, ethyl acetate,and n-butanol soluble sfractions showed excellent activites against Escherichia coli, Shigella dysenteriae, Salmonella typhi, and Bacillus subtilis. Similarly the crude n-hexane and chloroform fractions were also found to have significant activity against fungal strains including Fusarium solani, Aspergillus flexneri, and Aspergillus flavus.

Conclusion: Oxalis corniculata is a common medicinal plant widely used against numerous infectious diseases. The two isolated compounds 5hydroxy-6,7,8,4'-tetra methoxy flavone and 5,7,4'-trihydroxy-6,8-dimethoxyflavone were evaluated for antibacterial and antifungal activities. The results showed that latter compound was more active than that of the former.

Keywords: Oxalis corniculata extract, Antibacterial cream, Anti-fungal

(C) 2020 The Authors. Published by Innovare Academic Sciences Pvt Ltd. This is an open access article under the CC BY license (http://creativecommons.org/licenses/by/4.0/) DOI: http://dx.doi.org/10.22159/ijcpr.2020v12i5.39763. Journal homepage: https://innovareacademics.in/journals/index.php/ijcpr

\section{INTRODUCTION}

Oxalis corniculata is an endangered and medicinally important plant indigenous to tropical and sub-tropical regions of the world,its medicinal usage is reported in Indian pharmaceutical codex, the Chinese, British and the American pharmacopoeias and in different traditional systems of medicines such as Ayurveda, Unani and Siddha. Wide ranges of phytochemical constituents have been isolated from the plant like flavanoids, tannins, phytosterols phenol, glycosides, fatty acids galactoglycerolipid and volatile oil. it is rich source of essential fatty acids like palmitic acid,oleic acid, linoleic, linolenic and stearic acids and it possess anti-bacterial, anti-inflammatory anti-oxidant properties [1]. Anti-bacterial cream is a medicated cream which is used to treat certain skin infections caused by bacteria, the topical cream can be used to treat certain skin infections and to prevent infections in burns, skin grafts, minor cuts, wounds [2]. Due to jumbled use of existing anti-microbial drugs pathogenic bacteria have developed resistance against wide range of antibiotics. Microbiologists from all over the world are in search to formulate new anti-microbial drugs and evaluate efficiency of plant products to replace chemical anti-microbial agents [3]. Medicinal plant extracts have shown to serve as a cheap source of anti-microbial agents against pathogenic microbes [4]. Literature review suggests that Handali et al. formulated an antibacterial cream form Oxalis cornichulata aqueous extract and found that it was effective against S. aureus and E. coli [5]. Raghavendra MP et al. formulated an antibacterial cream from Oxalis corniculata leaves and effect was compared with the marketed product [6].

The aim of the present study is to evaluate antibacterial and anti-fungal activities of different fractions of oxalis corniculata including methanol, n-hexane, chloroform, ethyl acetate and n-butanolsoluble fractions.

\section{MATERIALS AND METHODS}

\section{Extraction of oxalis corniculata}

The fresh leaves of plant oxalis corniculata were collected, washed thoroughly, dried in shadow and ground to powder. Take $10 \mathrm{~g}$ of the powder was macerated in $200 \mathrm{ml}$ boiling distilled water for $20 \mathrm{~min}$. The macerate was first filtered through muslin cloth and centrifuged at $3500 \mathrm{~g}$ for $15 \mathrm{~min}$. the supernant was removed by evaporation and stored in a suitable container. The extracted oxalis corniculata is stored in a suitable container and is added to the further cream base.

\section{Preparation of antibacterial cream}

Oil in water $(\mathrm{o} / \mathrm{w})$ emulsion-based cream was formulated. The oxalis extract other oil soluble components were dissolved in oil phase and heated to $75^{\circ} \mathrm{C}$. The water-soluble components were dissolves in water and heated to $75^{\circ} \mathrm{C}$. After heating, water phase was added slowly to oil phase with continuous stirring until cooling of emulsion took place. The oil and water phases and their quantities are listed below

Table 1: List of ingredients for formulation

\begin{tabular}{ll}
\hline Ingredients & Quantity \\
\hline stearic acid & $1.0 \mathrm{~g}$ \\
spermaceti/olive oil & $0.5 \mathrm{~g}$ \\
Cetyl alcohol & $0.5 \mathrm{~g}$ \\
Glycerine & $0.5 \mathrm{ml}$ \\
tri ethanolamine & $0.2 \mathrm{ml}$ \\
Benzyl alcohol & $0.2 \mathrm{ml}$ \\
Water & $7 \mathrm{ml}$ \\
\hline
\end{tabular}




\section{Evaluation of creams}

\section{Physical properties}

\section{Determination of organoleptic properties}

The Cream was observed for color, odour and appearance [7].

\section{pH of the cream}

The $\mathrm{pH}$ of various formulations was determined by using digital $\mathrm{pH}$ meter. About $1 \mathrm{~g}$ of the cream was weighed and dissolved in $100 \mathrm{~m}$ of distilled water and stored for two hours. The measurement of $\mathrm{pH}$ of each formulation was done in triplicate and average values were calculated [7].

\section{Test for thermal stability}

The formulated cream was inserting into glass bottle with the help of spatula, and taped to settle to the bottom. Filled up to two-third capacity of bottle and insert plug and tighten the cap. Filled bottle was kept erect inside the incubator at $4^{\circ} \pm 1^{\circ}$ for $48 \mathrm{~h}$. The sample passed the test, if on removal from the incubator shows no oil separation or any other phase separation $[8,9]$

\section{Irritancy}

Test Mark an area (1sq. $\mathrm{cm}$ ) on the left-hand dorsal surface. The cream was applied to the specified area and time was noted. Irritancy was checked up to $30 \mathrm{~min}$ and reported [8].

\section{Viscosity}

Viscosity of formulated cream was determined by book field viscometer at $50 \mathrm{rpm}$ [8]

\section{Spreadability}

The Spreadability was expressed in terms of time in seconds taken by two slides to slip off from the cream, placed in between the slides, under certain load. Lesser the time taken for separation of the two slides, better the Spreadability. Two sets of glass slides of standard dimensions were taken. The herbal cream formulation was placed over one of the slides. The other slide was placed on the top of the formulation, such that the cream was sandwiched between the two slides weight was placed upon the upper slides so that the cream between the two slides was pressed uniformly to form a thin layer. The weight was removed and the excess of formulation adhering to the slides was scrapped off. The upper slide allowed slipping off freely by the force of weight tied to it. The time taken for the upper slide was noted [10].

$$
\text { Spreadability }=\mathrm{m} \times \mathrm{l} / \mathrm{t}
$$

$\mathrm{m}=$ weight tied to the upper slide $(30 \mathrm{~g}) \mathrm{l}=$ length of glass slide $(5$ $\mathrm{cm}) \mathrm{t}=$ time taken in seconds.

\section{Phase separation}

The formulated cream was kept intact in a closed container at 25$300{ }^{\circ} \mathrm{C}$ not exposed tolight. Phase separation was observed carefully every $24 \mathrm{~h}$ for $30 \mathrm{~d}$. Any change in phaseseparation was checked [8].

\section{RESULTS AND DISCUSSION}

In our work we prepared nine (CC1-CC9) different cream formulations. Among these all formulations are tested for further final selection purpose.

\section{Physical properties}

The physical properties and all formulated cream were judged by its Color, Odour and texture.

The results are tabulated below.

\section{pH of the antibacterial cream}

The result of pH of prepared creams (CC1-CC9) was found to be around 6 which are suitablefor topical application. Because skin pH in between 4.5-6.

\section{Test for thermal stability}

Thermal stability of the formulation was determined by the humidity chamber controlled at $60-70 \% \mathrm{RH}$ and $37^{\circ} \mathrm{C}$. Finally all the formulations stable and no oil separation was observed.

\section{Irritability}

A small amount of gel was applied externally on the skin surface for few minutes and checked for reactions on the skin. It was found to be non-irritant.

\section{Viscosity}

Viscosity of formulated antibacterial cream was determined by brook field viscometer at $50 \mathrm{rpm}$. The viscosity of anti bacterial cream was found in range of 1000 to $3000 \mathrm{cp}$ which indicates that cream was easily spreadable by small amount of shear.

Table 2: Physical properties of cream

\begin{tabular}{|c|c|c|c|c|}
\hline Formulation code & Colour & Odour & Texture & Consistency \\
\hline CC1 & Cream white & Characteristic & Smooth & Semi solid \\
\hline $\mathrm{CC} 2$ & Cream white & Characteristic & Smooth & Semi solid \\
\hline CC3 & Cream white & Characteristic & Smooth & Semi solid \\
\hline CC4 & Cream white & Characteristic & Smooth & Semi solid \\
\hline CC5 & Cream white & Characteristic & Smooth & Semi solid \\
\hline CC6 & Cream white & Characteristic & Smooth & Semi solid \\
\hline CC7 & Cream white & Characteristic & Smooth & Semi solid \\
\hline CC8 & Cream white & Characteristic & Smooth & Semi solid \\
\hline CC9 & Cream white & Characteristic & Smooth & Semi solid \\
\hline
\end{tabular}

Table 3: pH of antibacterial cream

\begin{tabular}{ll}
\hline Formulation code & Ph \\
\hline CC1 & 7.21 \\
CC2 & 8.65 \\
CC3 & 7.72 \\
CC4 & 7.13 \\
CC5 & 6.65 \\
CC6 & 5.82 \\
CC7 & 5.14 \\
CC8 & 4.89 \\
CC9 & 5.55 \\
\hline
\end{tabular}




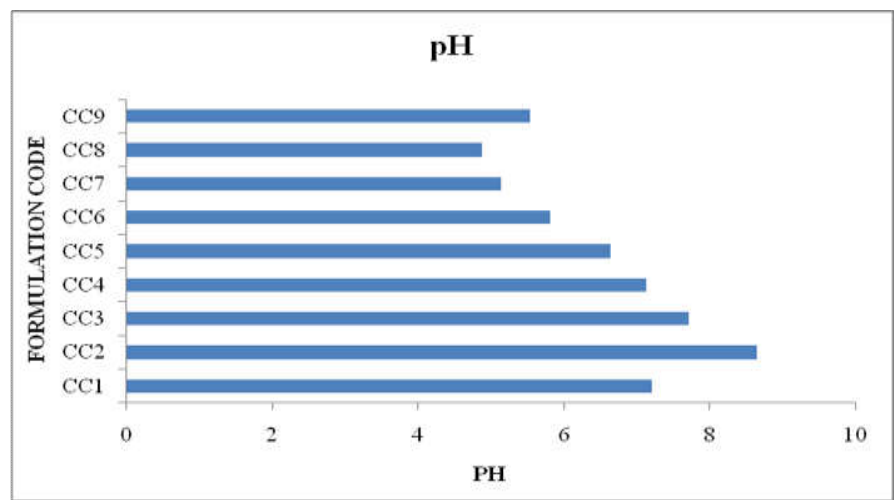

Fig. 1: $\mathrm{pH}$ of the antibacterial cream formulations

Table 4: Test for thermal stability of cream

\begin{tabular}{ll}
\hline Formulation code & Thermal stability \\
\hline CC1 & Stable \\
CC2 & Stable \\
CC3 & Stable \\
CC4 & Stable \\
CC5 & Stable \\
CC6 & Stable \\
CC7 & Stable \\
CC8 & Stable \\
CC9 & Stable \\
\hline
\end{tabular}

Table 5: Test for irritability of cream

\begin{tabular}{ll}
\hline Formulation code & Irritation \\
\hline CC1 & No \\
CC2 & No \\
CC3 & No \\
CC4 & No \\
CC5 & No \\
CC6 & No \\
CC7 & No \\
CC8 & No \\
CC9 & No \\
\hline
\end{tabular}

Fig. 2: Irritability test

Table 6: Viscosity of the cream

\begin{tabular}{ll}
\hline Formulation code & Viscosity (cp) \\
\hline CC1 & 1020 \\
CC2 & 1050 \\
CC3 & 1078 \\
CC4 & 1065 \\
CC5 & 1155 \\
CC6 & 1260 \\
CC7 & 1570 \\
CC8 & 1885 \\
CC9 & 1895 \\
\hline
\end{tabular}

cp: centipose

Table 7: Spread ability of antibacterial cream

\begin{tabular}{ll}
\hline Formulation code & Spread ability (cm) \\
\hline CC1 & 5.6 \\
CC2 & 5.8 \\
CC3 & 6.1 \\
CC4 & 6.5 \\
CC5 & 6.8 \\
CC6 & 7.5 \\
CC7 & 10.6 \\
CC8 & 12.5 \\
CC9 & 14.3 \\
\hline
\end{tabular}




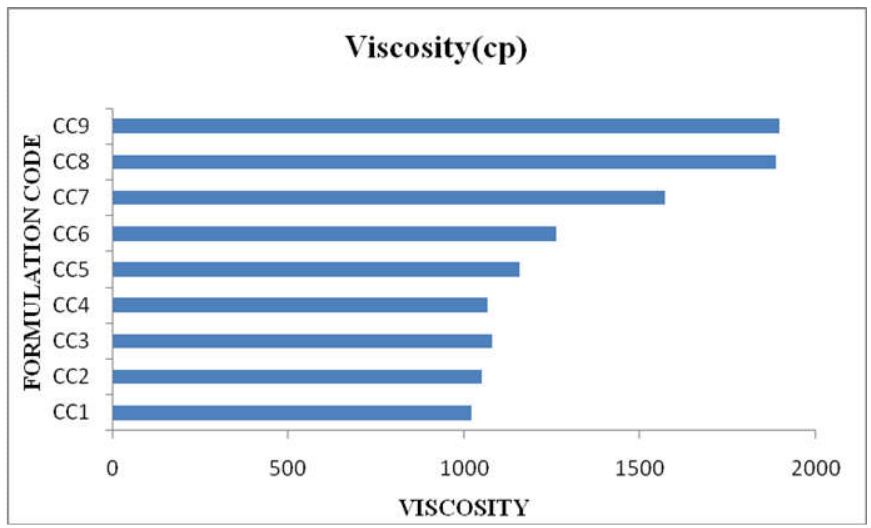

Fig. 3: Viscosity of antibacterial cream

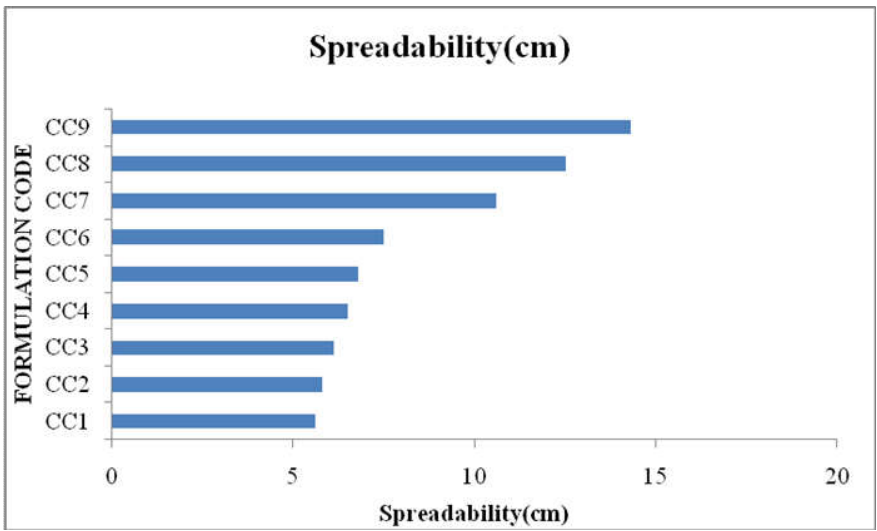

Fig. 4: Spreadability of antibacterial cream

Table 8: Phase separation of antibacterial cream

\begin{tabular}{ll}
\hline Formulation code & Phase separation \\
\hline CC1 & No \\
CC2 & No \\
CC3 & No \\
CC4 & No \\
CC5 & No \\
CC6 & No \\
CC7 & Yes \\
CC8 & Yes \\
CC9 & Yes \\
\hline
\end{tabular}

From the above results, CC6 Formulation was considered as optimized formulation. Which contains stearic acid 1.0 g, cetyl alcohol 0.5 , tri ethanol amine $0.2 \mathrm{ml}$, benzyl alcohol $0.2 \mathrm{ml}$ Olive oil $4 \mathrm{ml}$.

\section{Spreadability}

Spreadability of cream formulations, that is, the ability of a formulated cream to evenly spread on the skin plays an important role. Formulations CC6, CC5 were good spreadability properties. CC7-CC9 Formulations have leaking and overspreading occurred.

\section{Phase separation}

In these antibacterial cream formulations (CC1-CC5) no phase separation was observed.

\section{Antibacterial assay}

\section{This test is carried out by preparing bacterial inoculums}

The bacterial strains were subcultured to get fresh cultures of bacteria. for this purpose, a single colony from bacterial strain was inoculated on nutrient broth. The broth was incubated for $24 \mathrm{~h}$ at
$37{ }^{\circ} \mathrm{C} .14$ gm of nutrient agar media was dissolved in $1 \mathrm{~L}$ of distilled water at PH 7 and autoclaved for $20 \mathrm{~min}$ at $121{ }^{\circ} \mathrm{C}$. The media were allowed to cool down to $45{ }^{\circ} \mathrm{C}$ and poured to petri plates for preparing $75 \mathrm{ml}$ of solid media. using sterile cork borer 7 wells per plate were made in the solidified media. Agar diffusion method was used for antibacterial activity. Bacterial culture was inoculated on the surface of solid media. The crude extract of oxalis corniculata and fractions were dissolved in dimethylsulfoxide (DMSO) at the same concentration of $2 \mathrm{mg} / \mathrm{ml}$ to prepare stock solutions. from the stock solution, $1000 \mathrm{ul}$ was poured into respective wells [11]. Cefixime was used as a positive control and DMSO was used as a negative control. The zone of inhibition of crude extract and fractions were measured in $\mathrm{mm}$ after $24 \mathrm{~h}$ of incubation at $37{ }^{\circ} \mathrm{C}$ and compared with the zone of inhibition of standard drug cefixime. The maximum antibacterial activity in $20 \%$ concentration of the plant was $19.33 \mathrm{~mm}$ diameter for E. coli [12]. 


\section{CONCLUSION}

The present study involves formulation and evaluation of antibacterial cream using leaves of Oxaliscorniculata and the study suggests that oxalis corniculata has good antibacterial, antifungal properties and can be used to treat various skin infections. The aqueous extract of oxalis corniculata exhibited strong antibacterial activity, especially with an increase of extract concentration. The results of different physical and chemical tests of cream showed that the formulation could be used topically in order to protect skin against damage caused by S. aureus, and E. coli. Various evaluation parameters have been studied providing satisfactory results and this study revealed that the developed herbal antibacterial cream formulation of Code CC6 i. e the $20 \%$ concentration of extract was comparatively better than other formulations. So it is considered as optimized formulation.

\section{DISCUSSION}

Our study aimed at formulating an antimicrobial cream for leaves of Oxalis corniculata and evaluating its efficacy. The results showcase antibacterial and antifungal properties of the extract which is similar to the other studies conducted on the same herb. It was found to be useful in skin infections caused by mainly S. aureus and E. coli and fungi as well. This paves way for future studies to be conducted on the same.

\section{ACKNOWLEDGEMENT}

The authors are thankful to God, the faculty and management of Bharat School of Pharmacy

\section{FUNDING}

Nil

\section{AUTHORS CONTRIBUTIONS}

All the authors have contributed equally.

\section{CONFLICT OF INTERESTS}

Declared none

\section{REFERENCES}

1. Hemant B, Mukesh Kumar Singh, Deepa Thakur, Tapan Kumar Giri, DK Tripathi. The botany, chemistry, pharmacological and therapeutic application of oxalis corniculata linn-a review. Int J Phytomed 2011;3:1-8.

2. Jain NK. Pharmaceutical product development. $1^{\text {st }}$ Ed. CBS Publisher and Distributors. New Delhi; 2002. p. 221-8.

3. S Maji, P Dandapat, D Oja. In vitro antimicrobial potentialities of different solvent extracts of ethnomedicinal plants against clinically isolated human pathogens. J Phytol 2010;2:57-64.

4. RA Khan, MR Khan, S Sahreen, J Bokhari. Antimicrobial and phytotoxic screening of various fractions of Sonchus asper. Afr J Biotechnol 2010;9:3883-7.

5. Hosseini H, handali S, Parishani MP, Ghezelbash GHR, Ameri A. A comparative study of antibacterial effects of aqueous extract of oxalis corniculata L. With antibacterial effects of common antibiotics in S. aureus and E. coli infections. J Med Plants 2001;9:103-7.

6. Raghavendra MP, Staish S, Raveesha A. Phytochemical analysis and antibacterial activity of oxalis corniculata; a known medicinal plant. My Sci 2006;1:72-8.

7. Hsieh PC, Mau JL, Huang SH. Antimicrobial effect of various combinations of plant extracts. Food Microbiol 2001;18:35-43.

8. Lachman L, Lieberman HA, Kanig JL. The theory and practice of industrial pharmacy. $3^{\text {rd }}$ ed. USA, Lea and Febiger; 1986. p. 52633.

9. Handalimoghimipour E. Formulation and evaluation of antibacterial cream from oxalis corniculata aqueous extract. Jundishapur J Microbiol 2011;4:255-60.

10. Paul B. Encyclopedia of emulsion technology. $1^{\text {st }}$ ed. USA Marcel Decker Inc; 1993;1:131-405

11. M Khan, RA Qureshi, SA Gillani, F Ullah. Antimicrobial activity of selected medicinal plants of Margalla hills, Islamabad, Pakistan. J Med Plant Res 2011;5:4665-70.

12. Moghimipour E, Ameri A, Saudatzadeh A, Salimi A, Siahpoosh A Formulation of an anti-dermatophyte cream from eucalyptus camadulensis methanolic extract. Jundishapur J Natural Pharm Products 2009;4:32-40 